\title{
Isolated Boost Converter with Bidirectional Operation for Supercapacitor Applications
}

\author{
Juan C. Hernandez ${ }^{\dagger}$, Maria C. Mira ${ }^{*}$, Gökhan Sen", Ole C. Thomsen*, and Michael A. E. Andersen ${ }^{*}$ \\ $\dagger^{\dagger *}$ Technical University of Denmark, Kgs. Lyngby, Denmark
}

\begin{abstract}
This paper presents an isolated bidirectional dc/dc converter based on primary parallel isolated boost converter (PPIBC). This topology is an efficient solution in low voltage high power applications due to its ability to handle high currents in the low voltage side. In this paper, the converter has been modeled using non-ideal components and operated without any additional circuitry for startup using a digital soft-start procedure. Simulated and measured loop gains have been compared for the validity of the model. On-the-fly current direction change has been achieved with a prototype interconnecting two battery banks. A second prototype has been constructed and tested for supercapacitor operation in constant power charge mode.
\end{abstract}

Key words: Battery, Bidirectional, Isolated, Modeling, Startup, Supercapacitor

\section{NOMENCLATURE}

$R_{D_{\text {Bat }}}$

$V_{O C_{B a t}}$

$R_{E S R}$

$V_{S C}$

$r_{L}$

$r_{M P}$

$r_{p}$

$r_{S}$

$r_{M S}$

$r_{E S R}$

Battery dynamic resistance

Battery open circuit voltage

Supercapacitor voltage

Inductor parasitic resistance

Capacitor series resistance
Supercapacitor series resistance

Primary MOSFETs on resistance

Transformer primary resistance

Transformer secondary resistance

Secondary MOSFETs on resistance

\section{INTRODUCTION}

Nowadays the depletion of fossil fuels together with the awareness of the climate change is forcing the industry to move towards green energy solutions. The same change is starting to be a reality in transportation industry where hybrid and electric vehicles are presented as an alternative solution to $\mathrm{CO} 2$ emission reduction. Extension of the driving range in electric vehicles has become one of the main concerns to make this an attractive technology. Special efforts have been taken to improve the capacity of the energy storage elements and to increase the efficiency of all the parts inside the power drive train. Regenerative brakin $g$ is one of the adopted solutions for increasing the driving range by recovering the

Manuscript received Jan. 24, 2013; revised Mar. 15, 2013

Recommended for publication by Associate Editor Jin Hur.

†Corresponding Author: jchbo@elektro.dtu.dk

Tel: +45-45-25-36-81, Technical University of Denmark

*Technical University of Denmark, Denmark

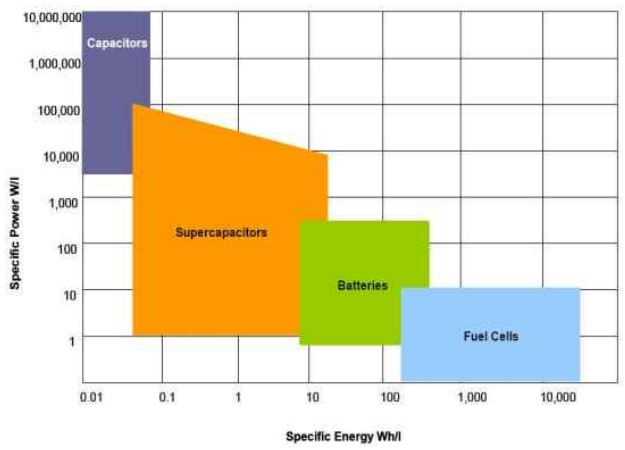

Fig. 1. Ragone chart. Power density vs. energy density for various energy storage systems [1].

kinetic energy of the vehicle during the braking process.

Supercapacitors have relatively large power density, as shown in Fig. 1, and are the preferred energy storage elements in regenerative braking applications. The aim of this work is to integrate a supercapacitor bank in a fuel cell powered drive train (Fig. 2) to increase the dynamics and the power density of the system.

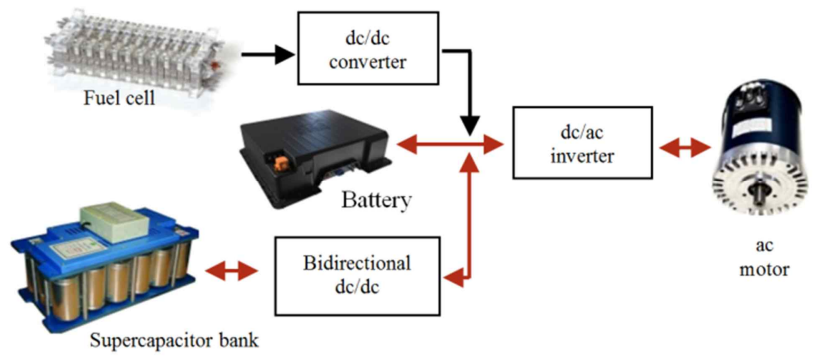

Fig. 2. Supercapacitor and bidirectional converter integration into a fuel cell powered drive train. 


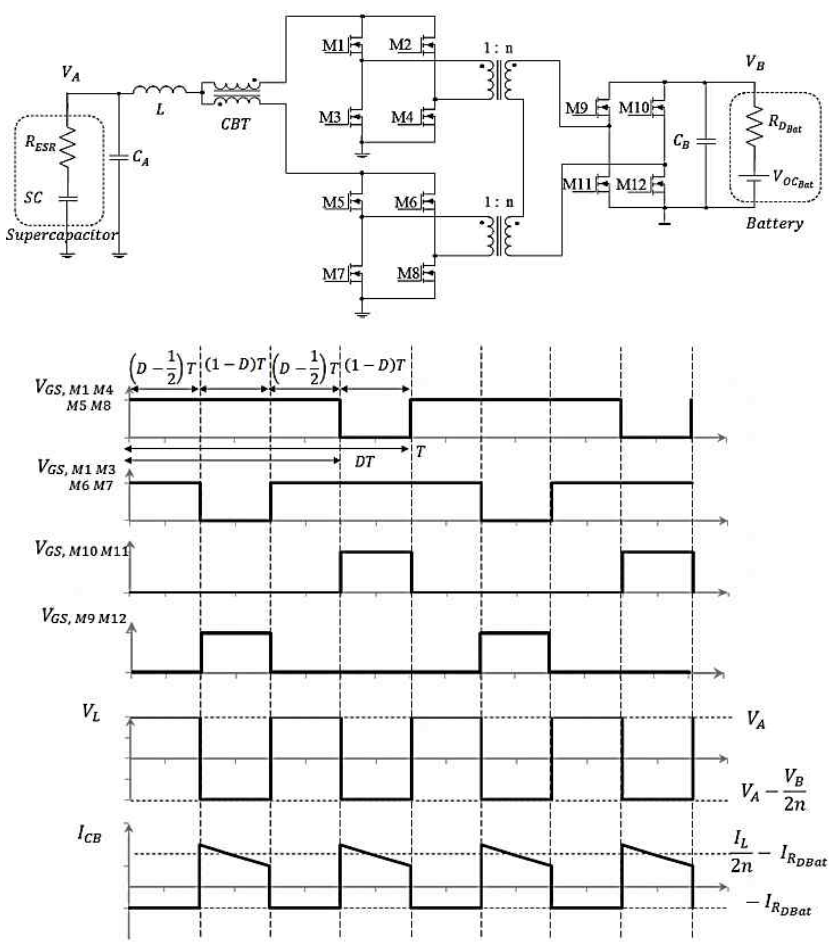

Fig. 3. Converter schematic (up) and boost mode steady state operating waveforms (down).

Different bidirectional dc-dc converter topologies have been proposed and investigated in the literature so far [2]-[7]. PPIBC is an efficient solution for low voltage high current applications [8]-[9]. Due to the transformer series connection on the secondary side, the current on each parallel primary stage is forced to be equal. However, different stray inductances in the current path or mismatches in the gate drive signal can cause the input current of each full bridge deviate from each other. In order to prevent this situation a current balancing transformer (CBT) is inserted to the circuit in series with the input inductor [10]. The CBT, which is implemented as an inverse coupled inductor, shows high impedance between the two parallel primary stages and keeps the branch currents to be equal. The schematic and waveforms of the proposed bidirectional converter are shown in Fig. 3.

In this topology, parallel primary power stages share the same control signals with the same phase switching sequence for the corresponding switches, which allows a simple control, similar to a simple isolated boost converter.
Output rectification unit as well as input and output filters are common to both of the parallel primary stages. The paralleling method splits the critical high ac-current-loop into two smaller loops. Each of the smaller loops only needs to switch half of the input current thereby achieving higher conversion efficiency. Since the two transformers share the same input current and have their secondary windings connected in series, a higher turns-ratio transformer can be replaced by two lower turns-ratio transformers, which allows a simple design and manufacturing of the transformers.

In this paper bidirectional operation of the PPIBC is studied. An accurate dynamic model of the converter has been derived taking into consideration the component non-idealities. Simple supercapacitor and battery models with internal impedances are also included in the model. PPIBC has been reduced to a simple boost converter in order to derive the state space equations.

Gain and phase plots of the compensated loop have been obtained from both the derived model and the experimental setup.

\section{CONVERTER MODELING}

Due to the large voltage time constant of batteries and supercapacitors, for small signal modeling purposes, these components can be treated as ideal voltage sources with an equivalent series resistance. Dc-dc converters interfacing this kind of energy storage elements need to be designed based on an accurate small signal model. This is due to the fact that the low value of the supercapacitor and battery series resistance makes the current flow in the converter to be very sensitive to duty cycle perturbations [11].

State space average modeling has been used to obtain an accurate model that predicts the dynamics of the system in a precise way. The converter parasitic resistances have been included in the model since they are in the same range with the battery and supercapacitor series resistances. Consequently, not considering these parasitics will have an effect on the dc gain of the plant transfer functions.

Fig. 4 shows the first state of the converter that corresponds to the charging state in boost mode and the discharging state in buck mode. Fig. 5 shows the simplified version of Fig. 4 where the two transformers are combined into an equivalent transformer with a turn ratio of $1: 2 \mathrm{n}$. All the components are reflected to the inductor side and parasitic resistances are combined into an equivalent resistance $\left(r_{e q 1}\right)$.

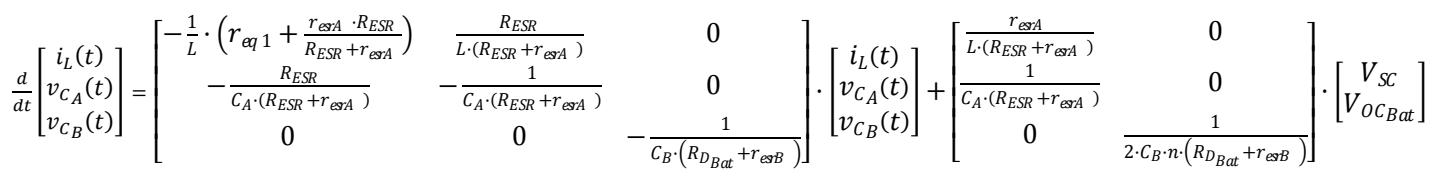

$$
\begin{aligned}
& V_{B}(t)=\left[\begin{array}{lll}
0 & 0 & \frac{R_{D_{B a t}}}{R_{D_{B a t}}+r_{e s s} B}
\end{array}\right] \cdot\left[\begin{array}{c}
i_{L}(t) \\
v_{C_{A}}(t) \\
v_{C_{B}}(t)
\end{array}\right]+\left[\begin{array}{ll}
0 & \frac{r_{e s r B}}{2 \cdot n \cdot\left(R_{D_{B} a t}+r_{e s r B}\right)}
\end{array}\right] \cdot\left[\begin{array}{c}
V_{S C} \\
V_{O C_{B a t}}
\end{array}\right]
\end{aligned}
$$




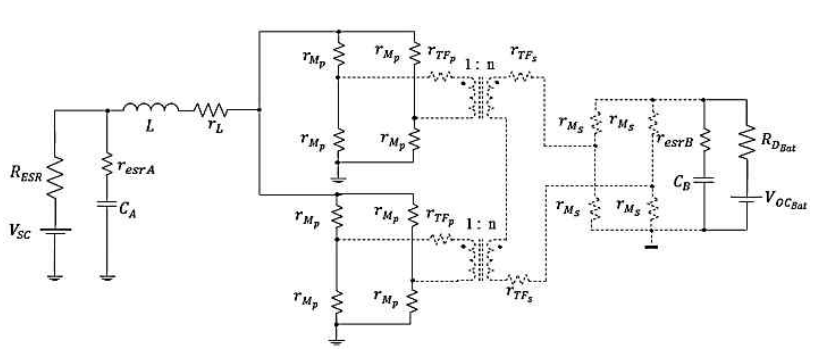

Fig. 4. Converter first state with parasitic resistances.

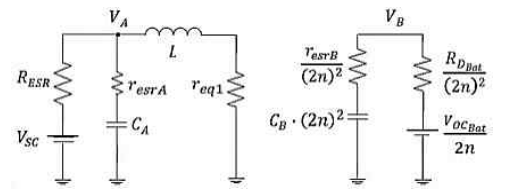

Fig. 5. Simplified equivalent circuit. Converter first state.

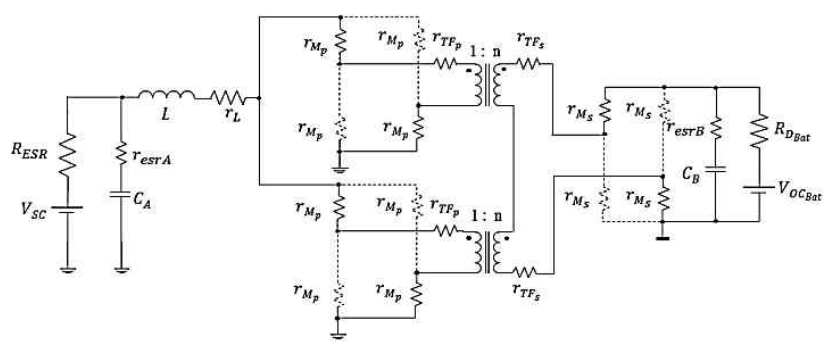

Fig. 6. Converter second state with parasitic resistances.

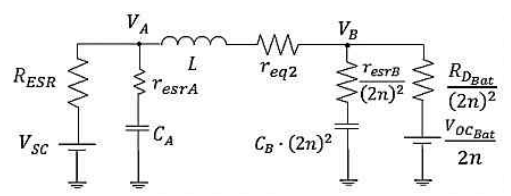

Fig. 7. Simplified equivalent circuit. Converter second state.

Fig. 6 presents the second state of operation corresponding to the discharging state of the boost mode and the charging state of the buck mode. Similar to the previous state the circuit is reduced to a simpler form as shown in Fig. 7.

The equivalent resistances in Fig. 5 and Fig. 7 are given by (1) and (2).

$$
\begin{gathered}
r_{e q 1}=r_{L}+r_{M_{P}} / 2 \\
r_{e q 2}=r_{L}+r_{M_{P}}+\frac{r_{P}}{2}+\frac{2 r_{S}}{(2 n)^{2}}+\frac{2 r_{M_{S}}}{(2 n)^{2}}
\end{gathered}
$$

Based on the simplified circuits for both operating states, the state and output matrixes can be written in the form of (3) and (4) as in (5) and (6) for the first converter state.

$$
\begin{gathered}
\frac{d x(t)}{d t}=A_{1} x(t)+B_{1} u(t) \\
V_{B}(t)=q_{1} x(t)+k_{1} u(t)
\end{gathered}
$$

In the same way, (7) and (8) can be obtained as shown in (9) and (10) for the second converter state.

$$
\begin{gathered}
\frac{d x(t)}{d t}=A_{2} x(t)+B_{2} u(t) \\
V_{B}(t)=q_{2} x(t)+k_{2} u(t)
\end{gathered}
$$

The state, input and output matrixes are obtained by averaging the individual matrixes for each state over a period as shown in (11), (12), (13) and (14).

$$
\begin{aligned}
& A=A_{1} \cdot d+A_{2} \cdot(1-d) \\
& B=B_{1} \cdot d+B_{2} \cdot(1-d) \\
& q=q_{1} \cdot d+q_{2} \cdot(1-d) \\
& k=k_{1} \cdot d+k_{2} \cdot(1-d)
\end{aligned}
$$

After perturbing the circuit around a steady state operating point, the first order terms are collected to obtain the linear model as in (15) and (16).

$$
\begin{aligned}
& \dot{\hat{x}}=A \cdot \hat{x}+B \cdot \hat{u}+\left[\left(A_{1}-A_{2}\right) X+\left(B_{1}-B_{2}\right) \cdot U\right] \cdot \hat{d} \\
& \hat{v}_{b}=q \cdot \hat{x}+k \cdot \hat{u}+\left[\left(q_{1}-q_{2}\right) X+\left(k_{1}-k_{2}\right) \cdot U\right] \cdot \hat{d}
\end{aligned}
$$

The term $X$ corresponds to the steady state solution given in (17).

$$
X=-A^{-1} \cdot B \cdot U
$$

Finally the small signal expressions of the state variables and the high side output voltage can be obtained by making $\hat{u}$ equal to zero and applying the Laplace transformation to (15) and (16) obtaining (18) and (19) respectively.

$$
\begin{aligned}
\hat{x}= & (s-A)^{-1} \cdot\left[\left(A_{1}-A_{2}\right) X+\left(B_{1}-B_{2}\right) U\right] \cdot \hat{d} \\
\hat{v}_{b}= & {\left[q \cdot(s-A)^{-1} \cdot\left[\left(A_{1}-A_{2}\right) X+\left(B_{1}-B_{2}\right) U\right]\right] . } \\
& {\left[+\left[\left(q_{1}-q_{2}\right) X+\left(k_{1}-k_{2}\right) \cdot U\right]\right] \cdot \hat{d} }
\end{aligned}
$$

The derived equations are valid independent of the power flow direction because the same differential equations govern the circuit for buck and boost operation modes. For this reason a single model is derived for both operating modes. In other words, if we consider the boost operating mode, the inductor charging subinterval is defined as $d T$ which corresponds to discharging subinterval for buck mode defined

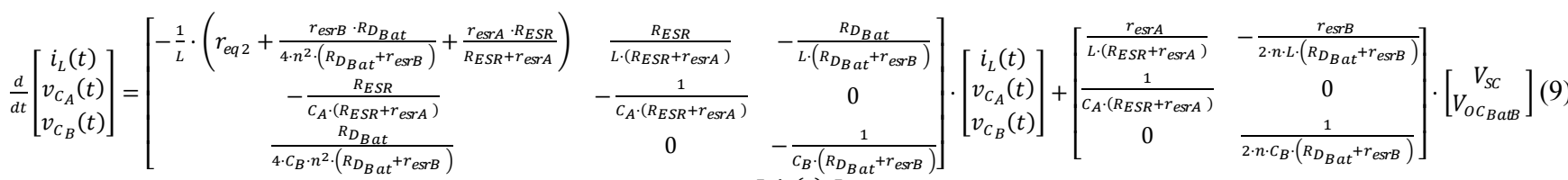

$$
\begin{aligned}
& V_{B}(t)=\left[\begin{array}{lll}
\frac{R_{D_{B a t}} r_{e s r B}}{4 \cdot n^{2} \cdot\left(R_{D_{B a t}}+r_{e s s B}\right)} & 0 & \frac{R_{D_{B a t}}}{R_{D_{B a t}}+r_{e s r}}
\end{array}\right] \cdot\left[\begin{array}{c}
i_{L}(t) \\
v_{C_{A}}(t) \\
v_{C_{B}}(t)
\end{array}\right]+\left[\begin{array}{ll}
0 & \frac{r_{e s r B}}{2 \cdot n \cdot\left(R_{D_{B} a t}+r_{e s r B}\right)}
\end{array}\right] \cdot\left[\begin{array}{c}
V_{S C} \\
V_{O C_{B a t}}
\end{array}\right]
\end{aligned}
$$


TABLE I

CONVERTER Operation MODES

\begin{tabular}{ccc}
\hline \hline Boost Mode & & Buck Mode \\
\hline$d$ & $=$ & $1-d$ \\
$1-d$ & $=$ & $d$ \\
$A_{1}$ & $=$ & $A_{2}$ \\
$A_{2}$ & $=$ & $A_{1}$ \\
$B_{1}$ & $=$ & $B_{2}$ \\
$B_{2}$ & $=$ & $B_{1}$ \\
$A$ & $=$ & $A$ \\
$B$ & $=$ & $B$ \\
\hline \hline
\end{tabular}

as $(1-d) T$. This duality is valid for all the converter dynamic expressions between buck and boost operating modes. Consequently, the final state equations remain the same independent of the power flow direction as shown in Table I.

\section{CONTROL STRATEGY}

In this application, current control on the battery side is preferred in order to absorb and deliver the necessary current to the inverter during regenerative braking and acceleration events. In this operation mode the supercapacitor is charged and discharged with constant power between the nominal voltage and half the nominal voltage to avoid high current stress on the low voltage side. However, when the supercapacitor voltage is under half of the nominal value due to the effect of leakage currents during long periods of inactivity of the system, the supercapacitor will be charged with constant current by controlling the inductor current.

From the state variable solution (18), the duty cycle-toinductor current transfer function is obtained. Moreover, the duty cycle-to-high side output current can be obtained by dividing the duty cycle-to-high side voltage transfer function (19) by the battery dynamic resistance as shown in (20).

$$
G_{\mathbb{B}}(s)=\left.\frac{\hat{\imath}_{B}(s)}{\hat{d}(s)}\right|_{\widehat{u}=0}=\frac{G_{V B}(s)}{R_{d b a t}}
$$

LTspice IV simulations are performed to validate the derived model by comparing the gain and phase plots. The steady state value of the inductor current is selected to be $100 \mathrm{~A}$ in both power flow directions. The converter duty cycle is calculated from the dc steady state solution given in (17). The selected parameters for the simulations are presented in Table I.

Fig. 8 and Fig. 9 present the calculated and simulated gain and phase plots of the converter duty cycle-to-inductor current transfer function in boost and buck operation modes respectively. Very close matching between the simulation and the calculated model is achieved. It can be observed that the obtained plant transfer function is very similar for both
TABLE II

\begin{tabular}{cc} 
CONVERTER SiMULATION PARAMETERS \\
\hline \hline$L$ & $5 \mu \mathrm{H}$ \\
$r_{L}$ & $1 \mathrm{~m} \Omega$ \\
$I_{L}$ & $100 \mathrm{~A}$ \\
$n$ & $1 / 2$ \\
$V_{S C}$ & $30 \mathrm{~V}$ \\
$R_{E S R}$ & $10 \mathrm{~m} \Omega$ \\
$V_{O C_{B a t}}$ & $80 \mathrm{~V}$ \\
$R_{D_{B a t}}$ & $40 \mathrm{~m} \Omega$ \\
$r_{M P}$ & $10 \mathrm{~m} \Omega$ \\
$r_{p}$ & $5 \mathrm{~m} \Omega$ \\
$r_{M S}$ & $5 \mathrm{~m} \Omega$ \\
$C_{A}$ & $100 \mu \mathrm{F}$ \\
$r_{e s r A}$ & $2 \mathrm{~m} \Omega$ \\
$C_{B}$ & $200 \mu \mathrm{F}$ \\
$r_{\text {esrB }}$ & $1 \mathrm{~m} \Omega$ \\
\hline \hline
\end{tabular}

modes. Only a small difference in the low frequency gain between the two operating modes can be observed. This effect is produced by the voltage drop across the parasitic resistances of the system.

Fig. 10 and Fig. 11 show the comparison between the calculated and simulated duty cycle-to-high side output current transfer function. Equal than before very close matching between the simulation and the calculation is achieved. In this case, the dynamics of the system depend on the current flow direction because of the presence of a right half plane zero in boost operation mode.

\section{EXPERIMENTAL RESULTS}

The first PPIBC prototype is shown in Fig. 12. The converter is controlled by using a 32 bit fixed point DSP.

The two transformers are integrated into the same magnetic core structure. This integrated magnetic component is constructed with four halves of ELP64/10/50 based on N87 core material.

The input inductor is built using four halves of E64/10/50 based on 3F3 material. The windings in both magnetic components are implemented using PCB boards with FR4 material. The inductor current is sensed by a Hall Effect current transducer LAS100-TP. The current measurement is low pass filtered by a differential amplifier to avoid aliasing at the $\mathrm{ADC}$ input.

In order to test the bidirectional operation, the prototype is connected to two battery banks at the low and high voltage side. The battery bank on the low voltage side is formed by three series connected AGM batteries Haze HZB-EV12-26 


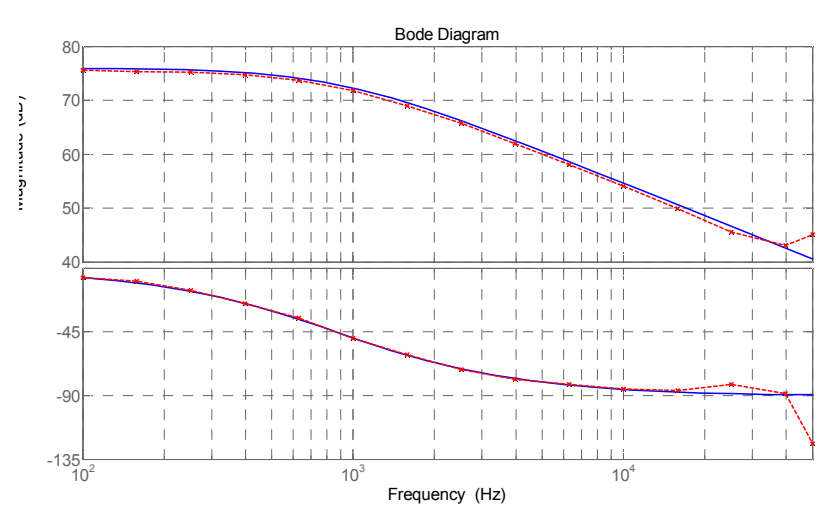

Fig. 8. Duty cycle-to-inductor current boost mode. Calculated (blue) and simulated (red).

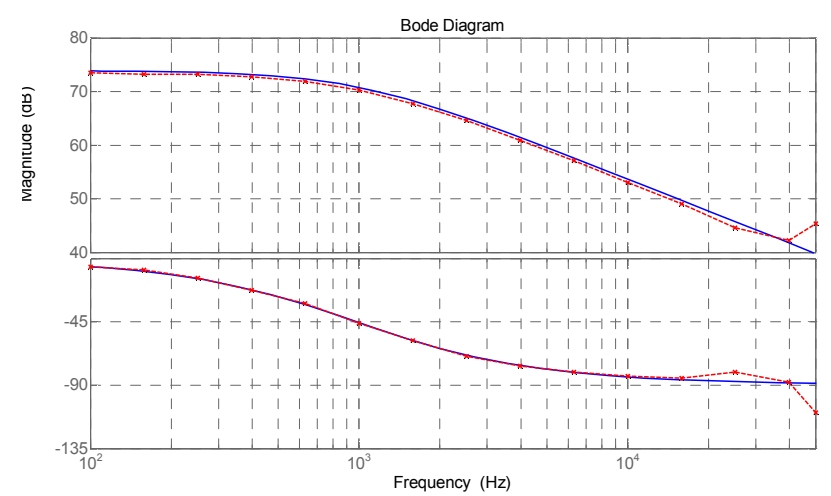

Fig. 9. Duty cycle-to-inductor current buck mode. Calculated (blue) and simulated (red).

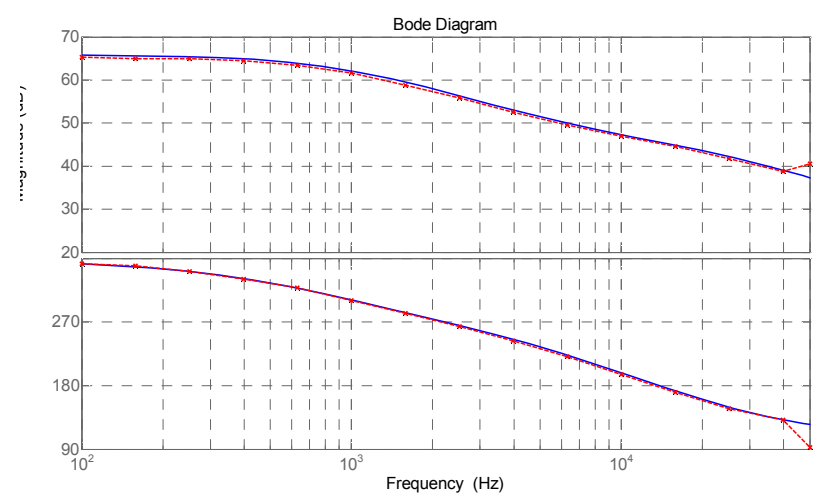

Fig. 10. Duty cycle-to-output current boost mode. Calculated (blue) and simulated (red).

which are rated for 12 volts and $26 \mathrm{Ah}$. On the high voltage side, the battery bank is composed of four series connected batteries of the same type. In this prototype, the inductor current is the selected control variable.

The battery impedance is measured and the obtained value at $1 \mathrm{kHz}$ is used in the derived dynamic model to match the gain at the desired converter crossover frequency. The converter parameters are shown in Table III and the parasitic resistances are presented in Table IV. The magnetic component parasitic resistances correspond to the measured values at $1 \mathrm{kHz}$.

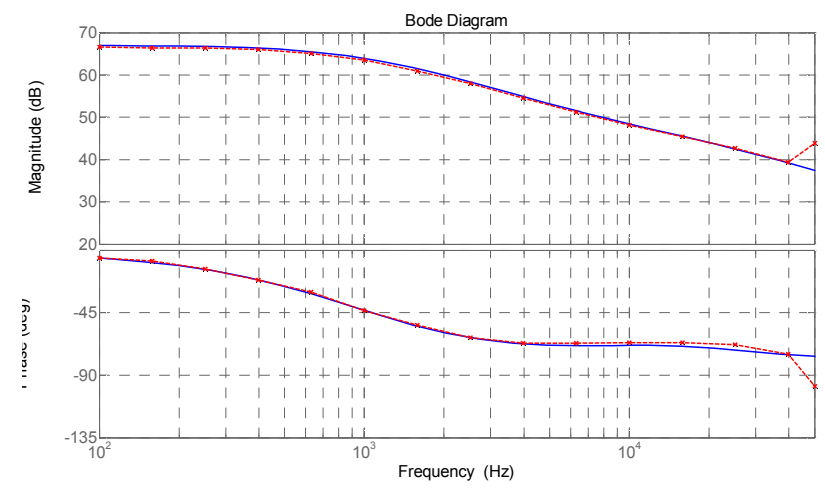

Fig. 11. Duty cycle to-output-current buck mode. Calculated (blue) and simulated (red).

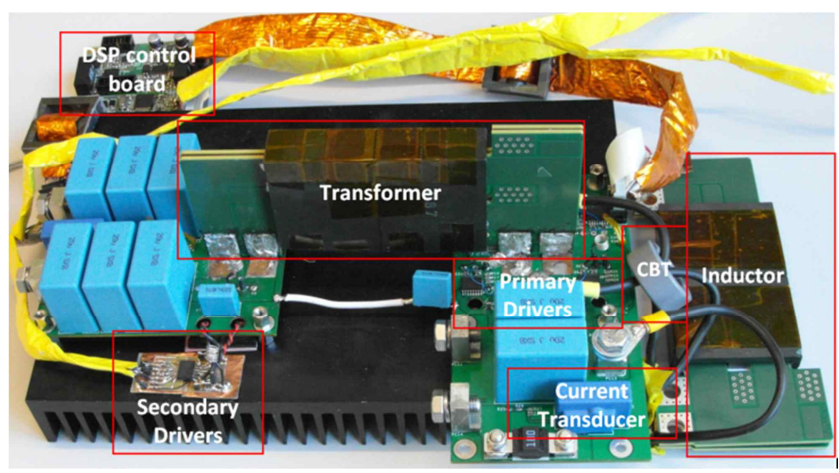

Fig. 12. First PPIBC prototype.

It is important to note that for calculating the dc operating point, the battery terminal voltage will change as a function of the current direction and magnitude as well as the battery state of charge (SOC). As presented in [12], the battery can be modeled as a dependent voltage source in series with the battery dynamic resistance. True understanding of the changes in the terminal voltages is possible through accurate modeling of the battery with capacitance-like effects of the battery internal chemistry, which is beyond the scope of this work.

In this paper the battery terminal voltages are measured at the desired operating conditions as shown in Table V. These values are used in the model to calculate the converter dc operating point.

The converter loop measurements are performed for both operating modes with a dc power supply as the input source to the converter and the corresponding battery bank as the converter load. The power supply output resistance is assumed to be negligible at the frequencies of interest. Moreover, it should to be noticed that the measured battery terminal voltages already include the voltage drop across the battery dynamic resistances.

The converter inductor current control loops are compensated by inserting an integrator and a zero before the lower frequency pole of the plant transfer function. Although 
TABLE III

PARAMETERS OF THE CONVERTER

\begin{tabular}{cc}
\hline \hline Battery A open circuit Voltage & $36 \mathrm{~V}$ \\
Battery B open circuit Voltage & $48 \mathrm{~V}$ \\
Transformer turn ratio & $1: 3$ \\
Inductor & $13.5 \mu \mathrm{H}$ \\
Transformer and inductor & Ferrite $3 \mathrm{~F} 3$ \\
core material & $40 \mu \mathrm{H}$ \\
Capacitor A & $120 \mu \mathrm{H}$ \\
Capacitor B & $\mathrm{IPA} 075 \mathrm{~N} 15 \mathrm{~N} 3 \mathrm{G}$ \\
Switches M1-M8 & FDH055N15A \\
Switches M9-M12 & $50 \mathrm{kHz}$ \\
Switching frequency & $60 \mathrm{~m} \Omega @ 1 \mathrm{kHz}$ \\
Battery A dynamic resistance & $80 \mathrm{~m} \Omega @ 1 \mathrm{kHz}$ \\
Battery B dynamic resistance &
\end{tabular}

TABLE IV

CONVERTER PARASITIC RESISTANCES

\begin{tabular}{cc}
\hline \hline$r_{L}$ & $3.9 \mathrm{~m} \Omega$ \\
$r_{M P}$ & $7.5 \mathrm{~m} \Omega$ \\
$r_{p}$ & $3.5 \mathrm{~m} \Omega$ \\
$r_{S}$ & $0.4 \mathrm{~m} \Omega$ \\
$r_{M S}$ & $5.9 \mathrm{~m} \Omega$ \\
$r_{\text {esrA }}$ & $3.15 \mathrm{~m} \Omega$ \\
$r_{\text {esrB }}$ & $1.1 \mathrm{~m} \Omega$ \\
\hline \hline
\end{tabular}

TABLE V

Converter Steady Operating CONDItions

\begin{tabular}{cc}
\hline \hline Boost Mode & Buck Mode \\
\hline$V_{G}=33.6 \mathrm{~V}$ & $V_{\text {BatA }}=41 \mathrm{~V}$ \\
$V_{\text {BatB }}=56.1 \mathrm{~V}$ & $V_{G}=48 \mathrm{~V}$ \\
$I_{L}=10 \mathrm{~A}$ & $I_{L}=-10 \mathrm{~A}$ \\
$d=0.604$ & $d=0.422$ \\
\hline \hline
\end{tabular}

the converter plant transfer function is the same regardless of the current direction, different controllers have been used for boost and buck operation modes. This is due to the fact that the converter dc operating point is changed due to the battery terminal voltage being dependent on the current direction, which affects the converter transfer function. The compensation gain has been adjusted for a loop crossover frequency of $1 \mathrm{kHz}$ for both operating modes.

Fig. 13 presents a measurement of the converter steady state waveforms. Fig. 14 and Fig. 15 show the calculated and

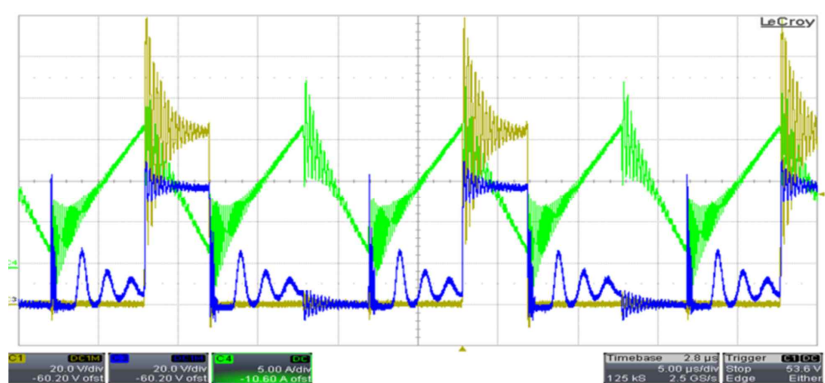

Fig. 13. Inductor current (green, $5 \mathrm{~A} / \mathrm{div}$ ) with low voltage side (light brown, 20V/div) and high voltage side (blue, 20V/div) drain to source voltage waveforms during steady state operation. Time scale: $5 \mu \mathrm{s} / \mathrm{div}$.

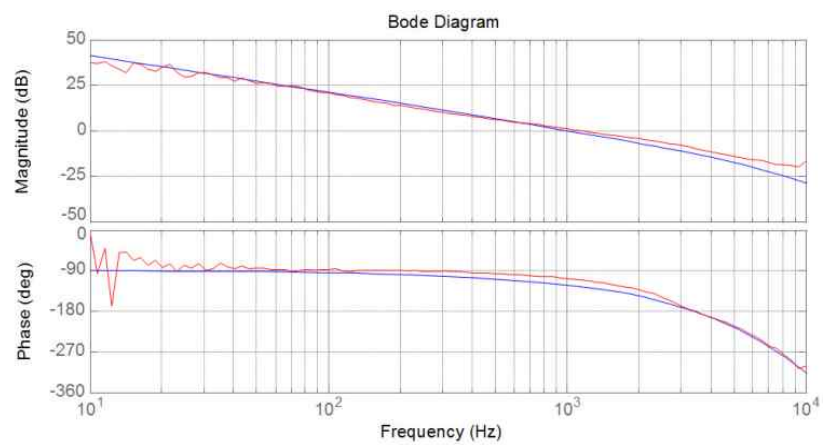

Fig. 14. Calculated (blue trace) and measured (red trace) open loop transfer function boost mode.

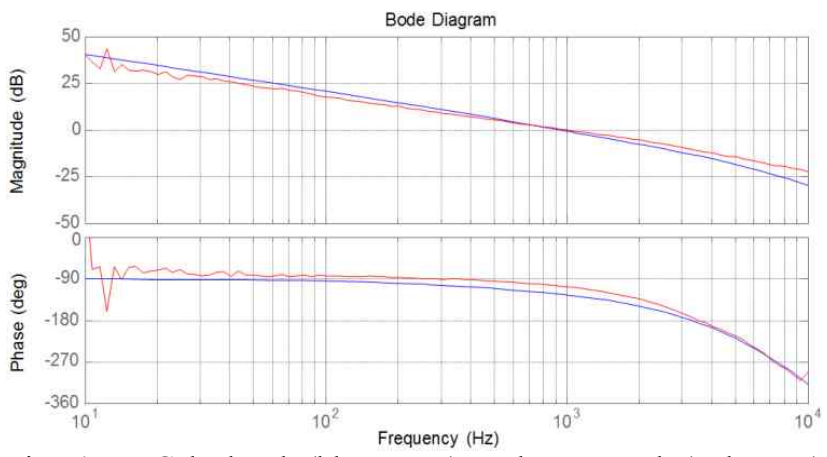

Fig. 15. Calculated (blue trace) and measured (red trace) open loop transfer function buck mode.

measured converter loop gain and phase plots where close matching can be observed. The calculated model includes the controller transfer function implemented inside the DSP with the sampling, calculation and PWM reconstruction delays, as well as the signal conditioning amplifier transfer function.

After designing the controllers for both operation modes, a soft start procedure of the converter needs to be implemented.

The implemented soft start function is able to turn on the converter in both directions without any additional circuitry.

While working with batteries, the duty cycle to inductor current transfer function has a larger gain compared to a pure resistive load for the same power level, meaning that the inductor current is very sensitive to small duty cycle perturbations in case of battery applications [11]. The converter has to be started with minimum duty cycle without 


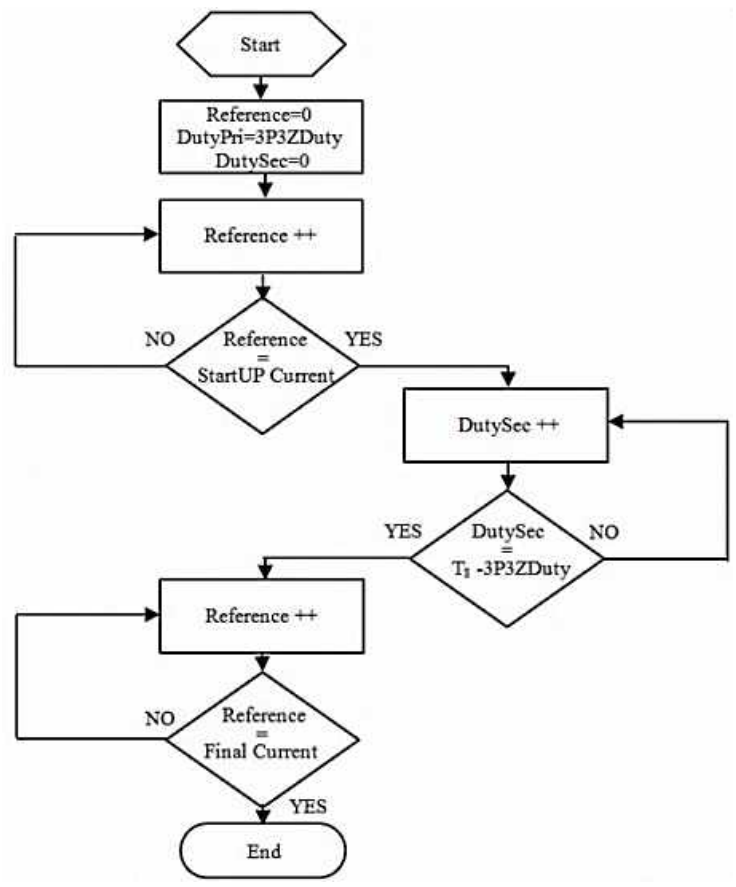

Fig. 16. Converter soft start flow diagram.

using synchronous rectification. Otherwise, starting with minimum duty cycle on one side will correspond to maximum duty cycle to the other side, creating an uncontrolled amount of initial current flow in the incorrect direction during converter startup. To avoid this situation, the converter should first be started by raising the current reference up to a certain startup current level. This current level has to be big enough to ensure CCM operation of the converter; otherwise, if the synchronous rectification is initiated, the duty cycle-to-inductor current transfer function will present a difference in dynamic behavior between DCM and CCM operation, resulting in an uncontrolled current increase until the control loop manages to compensate the error. Once the current trough the inductor has reached the desired level which ensures CCM operation, synchronous rectification can be started. At this point, the duty cycle for the synchronous MOSFETs is increased very slowly from zero to the final value calculated by the control law. This progressive introduction of the synchronous rectification avoids the current level to change again because of the difference in conduction resistance between the MOSFETs and the body diodes (used during normal rectification) that will affect the converter steady state conditions.

Once the synchronous rectification has been introduced, the final step is to increase the reference value up to the desired final current level. This soft start procedure removes unnecessary current and voltage stress from the switches at the start up increasing the converter reliability. The flow diagram of the proposed soft start procedure is presented in Fig. 16.

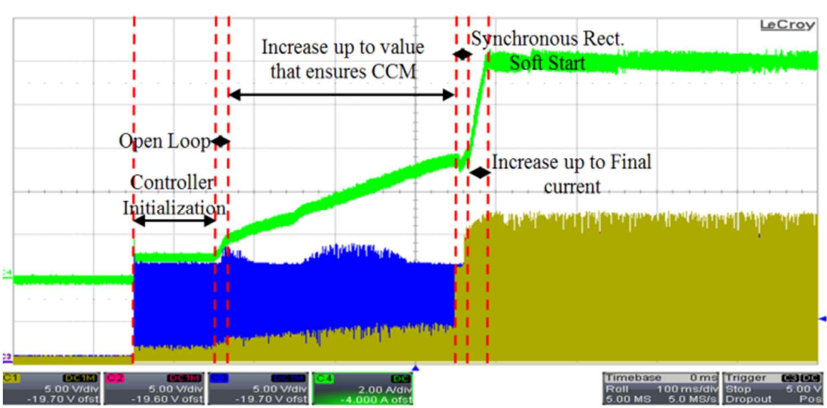

Fig. 17. Converter gradual soft start with two level inductor current reference change (green, $2 \mathrm{~A} / \mathrm{div}$ ). Low voltage side MOSFETs gate waveform (blue, $5 \mathrm{~V} / \mathrm{div}$ ) and high voltage side MOSFETs gate waveform (light brown, 5V/div.)Time scale: $100 \mathrm{~ms} / \mathrm{div}$.

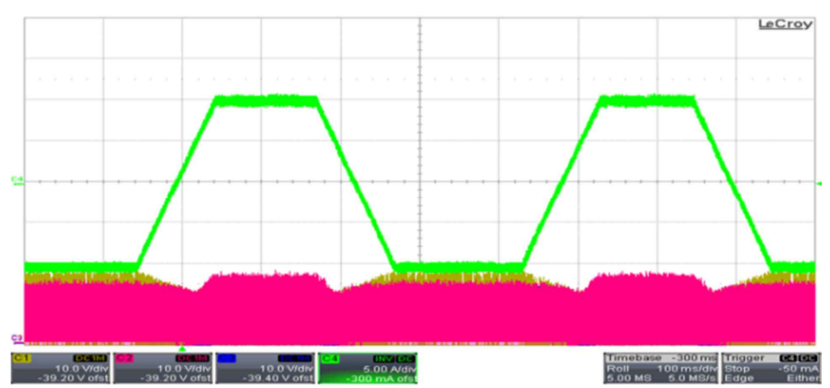

Fig. 18. Inductor current direction change with a defined ramp (5A/div. Time scale: $100 \mathrm{~ms} / \mathrm{div}$ ).

Fig. 17 shows the detailed startup sequence where the converter input current on the low voltage side together with the gate waveforms of the MOSFETs can be observed. Fig. 18 shows the bidirectional operation of the converter with average inductor current control. The figure shows four current direction change events where the current change transition time has been adjusted to $100 \mathrm{~ms}$.

After testing the soft start procedure and the bidirectional operation of the converter, a second PPIBC prototype with an input power of $8 \mathrm{~kW}$ is constructed. This converter is used for testing operation with a supercapacitor module with constant power charge by controlling the high side output current of the converter. The prototype is implemented by using copper foil windings in the magnetic components and interconnections.

The two transformers with $n=1 / 2$ are constructed using a stacked structure with four halves of E64/10/50 in 3F3 material. The input inductor is constructed with a Kool $\mathrm{Mu}$ core from Magnetics K6527E040. The converter prototype is shown in Fig. 19.

The converter is operated with a supercapacitor module from Maxwell BMOD0130 P056 B03 rated $56 \mathrm{~V}$ and $130 \mathrm{~F}$.

A controller composed of an integrator and a zero is designed and the loop crossover frequency is adjusted to $1 \mathrm{kHz}$ for $V_{B}=80 \mathrm{~V}$ and $V_{S C}=28 \mathrm{~V}$ with an average inductor current of $I_{L}=285 \mathrm{~A}$. The duty cycle-to-output current transfer function has its maximum gain when the 


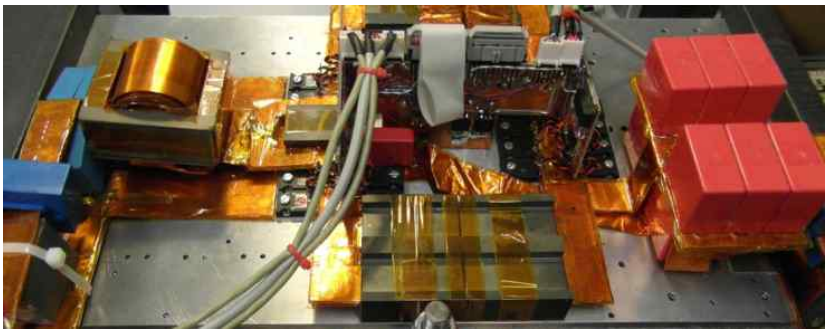

Fig. 19. Second PPIBC prototype.

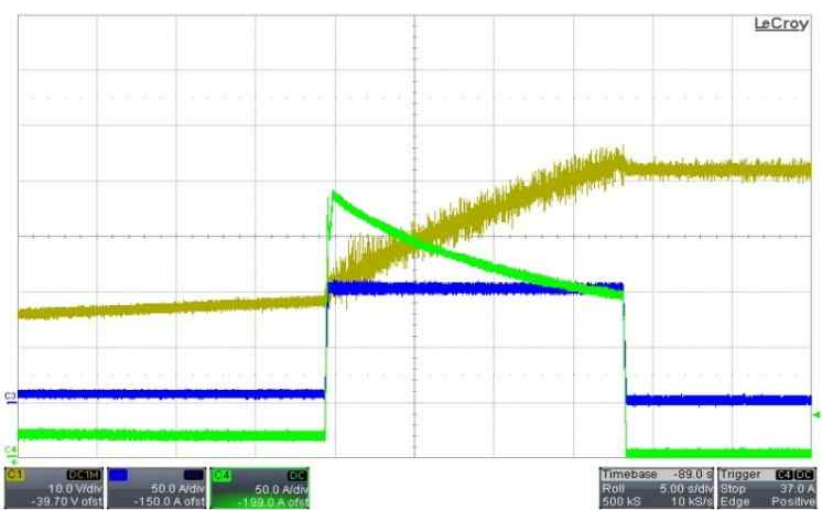

Fig. 20. Supercapacitor constant power charge event. Supercapacitor current (green, 50A/div). High side input current (blue, 50A/div) and supercapacitor voltage (light brown, 10V/div.)Time scale: $5 \mathrm{~s} / \mathrm{div}$.

supercapacitor voltage is minimum. Therefore, by adjusting the controller for these operating conditions, stable operation of the converter can be guaranteed for the whole operating voltage of the supercapacitor. Fig. 20 shows a supercapacitor charge event with a constant input power level of $8 \mathrm{~kW}$.

\section{CONCLUSIONS}

PPIBC is a high efficient isolated converter in low voltage high current applications. Bidirectional operation has been achieved by implementing synchronous rectification on the high voltage side. Accurate dynamic models have been derived and two different control strategies have been proposed for operation with supercapacitors.

Converter safe startup with batteries and supercapacitors regarding component stress is a non-trivial situation. The implemented DSP startup procedure proves that a soft start control of the current can be obtained and operation of the converter without any additional startup circuitry can be achieved.

The converter dynamic model has been shown to be the same independent of the power flow direction. The duty cycle-to-inductor plant transfer function is independent of the converter operating mode; therefore, a unified controller can be used for this control method. However, the duty cycle-to-output current transfer function dynamics present different behavior depending on the current flow direction due to the presence of a right half plane zero in boost operation mode. This situation forces the designer to implement two different controllers in order to maximize the dynamic performance of the control loops for each operation mode.

\section{REFERENCES}

[1] Odile Bertoldi and Sébastien Berger, "Report on Energy," Observatory Nano-European Commission, 2009.

[2] T. Mishima, E. Hiraki, T. Tanaka, and M. Nakaoka, "A new soft-switched bidirectional dc-dc converter topology for automotive high voltage dc us architectures," in Conf. Rec. of IEEE VPPC, pp. 1 - 6. Sep. 2006.

[3] H.-J. Chiu and L.-W. Lin, "A bidirectional dc-dc converter for fuel cell electric vehicle driving system," IEEE Trans. Power Electron., Vol. 21, No. 4, pp. 950-958, Jul. 2006.

[4] Z. Zhang, O. C. Thomsen, and M. A. E. Andersen, "Optimal design of push-pull-forward half-bridge (PPFHB) bidirectional dc-dc converter with variable input voltage," IEEE Trans. Ind. Electron., Vol.59, No.7, pp.2761-2771, Jul. 2012.

[5] Z. Zhang, Z. Ouyang, O. C. Thomsen, and M. A. E. Andersen, "Analysis and design of a bidirectional isolated dc-dc converter for fuel cells and super-capacitors hybrid system," IEEE Trans. Power Electron., Vol.27, No.2, pp. 848-859, Feb. 2012.

[6] Z. Ouyang, Z. Zhang, O. C. Thomsen, and M. A. E. Andersen, "Planar integrated magnetics (PIM) module in hybrid bidirectional DC/DC converter for fuel cell application," IEEE Trans. Power Electron., Vol. 26, No. 11, pp.3254-3264, Nov. 2011.

[7] F. Mihalič, Alenka Hren, "Safe start-up procedures of isolated bi-directional dc-dc converter," EPE-PEMC 2010, pp. 167-173, 2010.

[8] M. Nymand and M. A. E. Andersen, "New primary-parallel boost converter for high-power high-gain applications," in Proc. IEEE APEC 2009, pp. 35-39, 2009.

[9] M. Nymand and M. A. E. Andersen, "A new approach to high efficiency in isolated boost converters for high-power low-voltage fuel cell applications," Proc. EPE-PEMC, 2008.

[10] Gokhan Sen, S. M. Dehghan, Ole C. Thomsen, and Michael A. E. Andersen, "Comparison of current balancing configurations for primary parallel isolated boost converter," Acemp - Electromotion, 2011.

[11] Maria C. Mira A., Juan C. Hernandez B., Gokhan Sen, Ole C. Thomsen, and Michael A.E. Andersen, "Modeling and control of primary parallel isolated boost converter," IECON, 2012.

[12] Olivier Tremblay, Louis-A. Dessaint, and Abdel-Illah Dekkiche, "A generic battery model for the dynamic simulation of hybrid electric vehicles," VPPC 2007, pp 284-289, 2007.

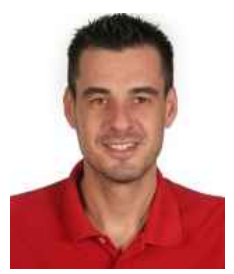

Juan C. Hernandez received the B.S. degree in Telecomunications from Miguel Hernandez University, Elche, Spain, in 2009 and the M.S. degree in electrical engineering from the Technical University of Denmark, Kongens Lyngby, Denmark, in 2012. He is currently working towards the $\mathrm{Ph} . \mathrm{D}$. degree at the Technical University of Denmark. His main research interests include modeling and control of switched mode converters, power factor correction and integration of wide bandgap switches in high power density power supplies. 


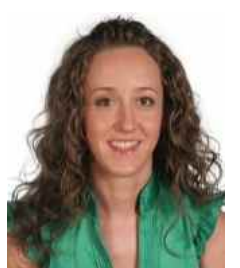

Maria C. Mira received the B.S. degree in Telecomunications from Miguel Hernandez University, Elche, Spain, in 2009 and the M.S. degree in electrical engineering from the Technical University of Denmark, Kongens Lyngby, Denmark, in 2012. She is currently working towards the Ph.D. degree at the Technical University of Denmark. Her main research interests include modeling and control of switched mode converters, bidirectional converters and multiport converters for renewable energies.

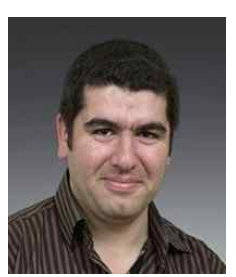

Gökhan Sen (S'08-M'13) received his BS degree in electrical and electronics engineering from Middle East Technical University (METU), Ankara, Turkey, in 2003. He was with Marmara Research Center, The Scientific and Technical Research Council of Turkey (TUBITAK) between 2003 and 2006. He obtained his MS degree from the University of Akron (UA), OH, USA in 2008, and his $\mathrm{PhD}$ degree from the Technical University of Denmark (DTU), Copenhagen, Denmark in 2012. He is presently an Assistant Professor in Faculty of Engineering, University of Turkish Aeronautics Association, Ankara, Turkey. His main research interests include power electronics, magnetic component design and renewable energy applications.

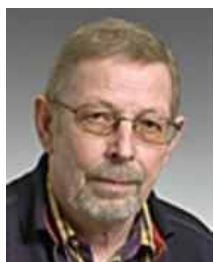

Ole C. Thomsen (M'06) received the B.S.E.E. degree in electronics from the Engineering Academy of Denmark (DIA), Kongens Lyngby, Denmark, in 1970.

From 1970 to 1976 , he was an RF R\&D Engineer with Skandinavisk Teleindustri A/S. From 1976 to 1980, he was the Power Electronic Project Manager with the Space Department, Christian Rovsing A/S. In 1980, he founded Powerlab A/S, operating within R\&D and Manufacturing of professional Power Electronic, and was here until 2004 as the General Manager. Since 2005, he has been with the Technical University of Denmark, Kongens Lyngby, where he is currently an Associate Professor. His main research interests include switch-mode power supplies, power factor correction, and electromagnetic compatibility.

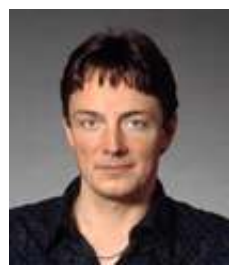

Michael A. E. Andersen (M'88) received the M.Sc.E.E. and Ph.D. degrees in power electronics from the Technical University of Denmark, Kongens Lyngby, Denmark, in 1987 and 1990, respectively. He is currently a Professor of power electronics at the Technical University of Denmark. Since 2009, he has been Deputy Director in the Department of Electrical Engineering. He is the author or coauthor of more than 100 papers. His research interests include switch-mode power supplies, piezoelectric transformers, power factor correction, and switch-mode audio power amplifiers. 